\title{
ARTICLE \\ Single Pt Atoms Supported on Oxidized Graphene as a Promising Catalyst for Hydrolysis of Ammonia Borane
}

\author{
Hong Wua ${ }^{a}$ Qi-quan Luo ${ }^{a}$, Rui-qi Zhang ${ }^{a}$, Wen-hua Zhang ${ }^{b, c, d *}$, Jin-long Yang ${ }^{a, c *}$ \\ a. Hefei National Laboratory for Physical Sciences at the Microscale, University of Science and Tech- \\ nology of China, Hefei 230026, China \\ b. Key Laboratory of Materials for Energy Conversion, Chinese Academy of Sciences, University of \\ Science and Technology of China, Hefei 230026, China \\ c. Synergetic Innovation Center of Quantum Information Quantum Physics, University of Science and \\ Technology of China, Hefei 230026, China \\ d. Department of Applied Mathematics, School of Physics and Engineering, Australian National Uni- \\ versity, Canberra, ACT 2600, Australia
}

(Dated: Received on April 11, 2018; Accepted on April 25, 2018)

Based on density functional theory calculations, the full hydrolysis of per $\mathrm{NH}_{3} \mathrm{BH}_{3}$ molecule to produce three hydrogen molecules on single Pt atoms supported on oxidized graphene $\left(\mathrm{Pt}_{1} / \mathrm{Gr}-\mathrm{O}\right)$ is investigated. It is suggested that the first hydrogen molecule is produced by the combination of two hydrogen atoms from two successive $\mathrm{B}-\mathrm{H}$ bonds breaking. Then one $\mathrm{H}_{2} \mathrm{O}$ molecule attacks the left ${ }^{*} \mathrm{BHNH}_{3}$ group ( ${ }^{*}$ represents adsorbed state) to form ${ }^{*} \mathrm{BH}\left(\mathrm{H}_{2} \mathrm{O}\right) \mathrm{NH}_{3}$ and the elongated $\mathrm{O}-\mathrm{H}$ bond is easily broken to produce ${ }^{*} \mathrm{BH}(\mathrm{OH}) \mathrm{NH}_{3}$. The second $\mathrm{H}_{2} \mathrm{O}$ molecule attacks ${ }^{*} \mathrm{BH}(\mathrm{OH}) \mathrm{NH}_{3}$ to form ${ }^{*} \mathrm{BH}(\mathrm{OH})\left(\mathrm{H}_{2} \mathrm{O}\right) \mathrm{NH}_{3}$ and the breaking of $\mathrm{O}-\mathrm{H}$ bond pointing to the plane of $\mathrm{Pt}_{1} / \mathrm{Gr}-\mathrm{O}$ results in the desorption of $\mathrm{BH}(\mathrm{OH})_{2} \mathrm{NH}_{3}$. The second hydrogen molecule is produced from two hydrogen atoms coming from two $\mathrm{H}_{2} \mathrm{O}$ molecules and $\mathrm{Pt}_{1} / \mathrm{Gr}-\mathrm{O}$ is recovered after the releasing of hydrogen molecule. The third hydrogen molecule is generated by the further hydrolysis of $\mathrm{BH}(\mathrm{OH})_{2} \mathrm{NH}_{3}$ in water solution. The rate-limiting step of the whole process is the combination of one $\mathrm{H}_{2} \mathrm{O}$ molecule and ${ }^{*} \mathrm{BHNH}_{3}$ with an energy barrier of $16.1 \mathrm{kcal} / \mathrm{mol}$. Thus, $\mathrm{Pt}_{1} / \mathrm{Gr}-\mathrm{O}$ is suggested to be a promising catalyst for hydrolysis of $\mathrm{NH}_{3} \mathrm{BH}_{3}$ at room temperature.

Key words: Density functional theory, Single atom catalysis, Platinum, Oxidized graphene, Ammonia borane hydrolysis

\section{INTRODUCTION}

Hydrogen is considered as one of the most potential clean and renewable energy carriers in future. Safe storage and transport of hydrogen is important for its real application [1]. It is expected that hydrogen is stored in types of stable materials under mild condition and can be released steadily by the trigger of catalysts $[1-5]$. Ammonia borane $\left(\mathrm{NH}_{3} \mathrm{BH}_{3}\right)$ is regarded as a promising candidate molecule for hydrogen storage due to its nontoxicity, high hydrogen content $(19.6 \mathrm{wt} \% \mathrm{H})$, and high thermal stability even in water solvent at ambient temperature [6-9]. The best scenario is that per $\mathrm{NH}_{3} \mathrm{BH}_{3}$ molecule can completely release three hydrogen molecules and can be recovered easily [3, 5-8]. Respect to direct dissociation of $\mathrm{NH}_{3} \mathrm{BH}_{3}$ at high temperature, hydrolysis of $\mathrm{NH}_{3} \mathrm{BH}_{3}$ on catalysts is more promising for room temperature hydrogen generation.

\footnotetext{
* Authors to whom correspondence should be addressed. E-mail: whhzhang@ustc.edu.cn, jlyang@ustc.edu.cn
}

Pt-based catalysts, such as small Pt nanoparticles supported on $\mathrm{SiO}_{2}[10], \gamma-\mathrm{Al}_{2} \mathrm{O}_{3}[10]$, porous chromium terephthalate (MIL-101) [11], carbon nanotubes (CNT) $[12,13]$, and reduced graphene oxide [14], exhibit superior catalytic activity for hydrolysis of $\mathrm{NH}_{3} \mathrm{BH}_{3}$. Transition non-noble metals such as Co [15-18], Ni [19-22], and $\mathrm{Cu}$ [23-25] are also widely studied to explore the possibility to replace noble metals for their low price. Both experimental and theoretical work were performed to better understand the hydrolysis mechanism of $\mathrm{NH}_{3} \mathrm{BH}_{3}$ and get clues for catalysts improvement. In early stage, it was proposed that the hydrolysis starts from the $\mathrm{B}-\mathrm{N}$ bond breaking by the attacking of water molecule [10] or the dissociation of $\mathrm{H}_{2} \mathrm{O}$ in the hydroxylation process of the adsorbed $\mathrm{NH}_{3} \mathrm{BH}_{x}$ from $\mathrm{B}-\mathrm{H}$ breaking [26]. Recently, the $\mathrm{O}-\mathrm{H}$ bond cleavage of water is experimentally suggested as the ratelimiting step of $\mathrm{NH}_{3} \mathrm{BH}_{3}$ hydrolysis on the $\mathrm{Pt} / \mathrm{CNT}$ [27], PtRu/CNT [28], Co/CTF [17], Ni/ZIF-8 [21], and atomically dispersed $\mathrm{Pt}$ on the surface of $\mathrm{Ni}$ particle [29], etc. by kinetic isotope effect (KIE) method. Theoretically, it is suggested that the rate-limiting step could be water assisted $\mathrm{B}-\mathrm{N}$ bond breaking [19], attacking of 
surfaced adsorbed $\mathrm{OH}$ group to break $\mathrm{B}-\mathrm{N}$ bond [30], and even the dissociation of an $\mathrm{O}-\mathrm{H}$ bond in $\mathrm{H}_{2} \mathrm{O}$ [29] for the production of the first hydrogen molecule. Moreover, the whole picture of the full hydrolysis of $\mathrm{NH}_{3} \mathrm{BH}_{3}$ with catalysts has not been provided yet.

Till now, the lack of abundance of Pt limits its practical use as catalysts and the catalytic performance of non-noble transition metals is relatively lower than that of Pt [31]. Searching for new types of catalysts is still demanding. An alternative way is to maximize the utilization of noble metal by downsizing the size of nanoparticles even to single atoms on designed substrates [32-34]. Reduced graphene oxide is a good candidate for substrates to anchor single metal atoms [35] for its large surface area, rich and controllable surface structures. Recently, the isolated Pt and Pd atoms supported on reduced graphene oxide have been successfully prepared and exhibited excellent catalytic activity for methanol oxidation [36] and selective hydrogenation of 1,3-butadiene at mild reaction conditions [37], respectively. Also, the isolated $\mathrm{Pt}$ anchored by two interfacial oxygen at the edge of reduced graphene oxide was active for the partial hydrolysis of $\mathrm{NH}_{3} \mathrm{BH}_{3}$ with about one hydrogen molecule released by per $\mathrm{NH}_{3} \mathrm{BH}_{3}$ molecule [38]. Considering the rich structure configurations on reduced graphene oxide, it is anticipated to design a configuration of single $\mathrm{Pt}$ atoms supported on reduced graphene oxide with high catalytic activity for the full hydrolysis of $\mathrm{NH}_{3} \mathrm{BH}_{3}$.

Herein, in this work we design a single Pt atom supported on trivacancy structure terminated by an oxygen adatom to form an ether group in graphene nanosheet $\left(\mathrm{Pt}_{1} / \mathrm{Gr}-\mathrm{O}\right) . \mathrm{Pt}_{1} / \mathrm{Gr}-\mathrm{O}$ catalyzed full hydrolysis process of $\mathrm{NH}_{3} \mathrm{BH}_{3}$ is studied, and it is found the rate limiting step is the hydratation of ${ }^{*} \mathrm{BHNH}_{3}$ with an energy barrier of $16.1 \mathrm{kcal} / \mathrm{mol}$. The low activation energy indicates that on $\mathrm{Pt}_{1} / \mathrm{Gr}-\mathrm{O}$ the full hydrolysis of $\mathrm{NH}_{3} \mathrm{BH}_{3}$ can proceed at room temperature. Thus $\mathrm{Pt}_{1} / \mathrm{Gr}-\mathrm{O}$ may be a promising catalyst for $\mathrm{NH}_{3} \mathrm{BH}_{3}$ hydrolysis.

\section{COMPUTATIONAL DETAILS}

All the calculations were performed by using spinpolarized density functional theory (DFT) method. The DFT semi-core pseudopotentials method (DSPP) [39] with a single effective potential replacing core electrons and the double numerical basis set together with polarization functions (DNP) were adopted to form the Perdew-Burke-Ernzerhof (PBE) exchange-correlation functional within the generalized gradient approximation (GGA) [40], implemented in $\mathrm{DMol}^{3}$ package $[41,42]$. A smearing of $0.005 \mathrm{Ha}(1 \mathrm{Ha}=27.21 \mathrm{eV})$ to the orbital occupation was applied to achieve electronic convergence in geometric optimization and transition state search program. The real-space global cutoff radius was set to be $4.5 \AA$. A hexagonal supercell containing $(6 \times 6)$ unit cells of graphene monolayer with $20 \AA$ vacuum layer was used as a support for a single $\mathrm{Pt}$ atom. The convergence tolerances of energy, force, and displacement for the geometry optimization were $1 \times 10^{-5} \mathrm{Ha}, 0.002 \mathrm{Ha} / \AA$, and $0.005 \AA$, respectively. In self-consistent-field ( $\mathrm{SCF}$ ) procedures a convergence criterion of $1 \times 10^{-6} \mathrm{Ha}$ and fermi occupation were adopted. $3 \times 3 \times 1 k$-points grid was used to describe the Brillouin zone for geometric optimization and self-consistent calculations. The transition state for each elementary step was determined by LST/QST method and confirmed via frequency calculations. The $\mathrm{H}_{2} \mathrm{O}$ solvent environment was simulated by using a conductor-like screening model (COSMO) [43] in all calculations. The dielectric constant was set to 78.54 for $\mathrm{H}_{2} \mathrm{O}$. To verify the accuracy of our calculation method, we calculated the $\mathrm{B}-\mathrm{N}$ bond breakage of $\mathrm{NH}_{3} \mathrm{BH}_{3}$ attacked by one $\mathrm{H}_{2} \mathrm{O}$ molecule in aqueous phase. The calculated energy barrier of $38.0 \mathrm{kcal} / \mathrm{mol}$ is close to that of $32.9 \mathrm{kcal} / \mathrm{mol}$ calculated at $\operatorname{CCSD}(\mathrm{T}) / / \mathrm{M} 06$ $2 \mathrm{X} / 6-311+\mathrm{G}(\mathrm{d}, \mathrm{p})$ level [44]. The adsorption energies of surface species are defined as:

$$
E_{\text {ads }}=E_{\mathrm{X} / \text { catalyst }}-\left(E_{\text {catalyst }}+E_{\mathrm{X}}\right)
$$

where $E_{\mathrm{X} / \text { catalyst }}, E_{\text {catalyst }}$, and $E_{\mathrm{X}}$ represent the energies of adsorbed systems, catalyst itself, and surface species, respectively. This hydrogen bond (H-bond) energy is calculated by the following formula:

$$
E_{\mathrm{H}-\text { bond }}=E_{* \mathrm{X} \cdots \mathrm{H}_{2} \mathrm{O}}-\left(E_{* \mathrm{X}}+E_{\mathrm{H}_{2} \mathrm{O}(\mathrm{l})}\right)
$$

where $E_{* \mathrm{X} \cdots \mathrm{H}_{2} \mathrm{O}}, E_{* \mathrm{X}}$, and $E_{\mathrm{H}_{2} \mathrm{O}(\mathrm{l})}$ represent the energies of the total systems, the adsorbed $\mathrm{X}$ species on $\mathrm{Pt}_{1} / \mathrm{Gr}-\mathrm{O}$, and a liquid phase $\mathrm{H}_{2} \mathrm{O}$ molecule $\left(\mathrm{H}_{2} \mathrm{O}(\mathrm{l})\right)$, respectively. ${ }^{*} \mathrm{X}$ denotes the adsorbed intermediates in the process of $\mathrm{NH}_{3} \mathrm{BH}_{3}$ hydrolysis. The total energy of $\mathrm{Pt}_{1} / \mathrm{Gr}-\mathrm{O}$ with one $\mathrm{NH}_{3} \mathrm{BH}_{3}$ and three $\mathrm{H}_{2} \mathrm{O}$ molecules in water solvent is set as zero point for the relative energy for $\mathrm{NH}_{3} \mathrm{BH}_{3}$ hydrolysis.

\section{RESULTS AND DISCUSSION}

\section{A. Adsorption on the $\mathrm{Pt}_{1} / \mathrm{Gr}-\mathrm{O}$ Surface}

A trivacancy with an edge ether on graphene basal plane (Gr-O) is designed to anchor a single Pt atom (denoted as $\left.\mathrm{Pt}_{1} / \mathrm{Gr}-\mathrm{O}\right)$. In the most stable configuration of $\mathrm{Pt}_{1} / \mathrm{Gr}-\mathrm{O}$ as shown in FIG. 1(a), the three Pt-C bond lengths are $1.92,1.95$, and $2.00 \AA$, respectively, which are shorter than the $\mathrm{Pt}-\mathrm{O}$ bond length of $2.14 \AA$. The binding energy of a single $\mathrm{Pt}$ atom respecting to $\mathrm{Pt}$ bulk is calculated as $-46.7 \mathrm{kcal} / \mathrm{mol}$, which can effectively prevent the aggregation of single $\mathrm{Pt}$ atoms.

In the most stable adsorption configuration of $\mathrm{NH}_{3} \mathrm{BH}_{3}$ on $\mathrm{Pt}_{1} / \mathrm{Gr}-\mathrm{O}$, a $\mathrm{NH}_{3} \mathrm{BH}_{3}$ molecule binds with $\mathrm{Pt}$ atom through two hydrogen atoms of $\mathrm{BH}_{3}$ group as shown in FIG. 1(b). The adsorption energy of $\mathrm{NH}_{3} \mathrm{BH}_{3}$ on $\mathrm{Pt}_{1} / \mathrm{Gr}-\mathrm{O}$ is calculated as $-9.8 \mathrm{kcal} / \mathrm{mol}$. The bond 

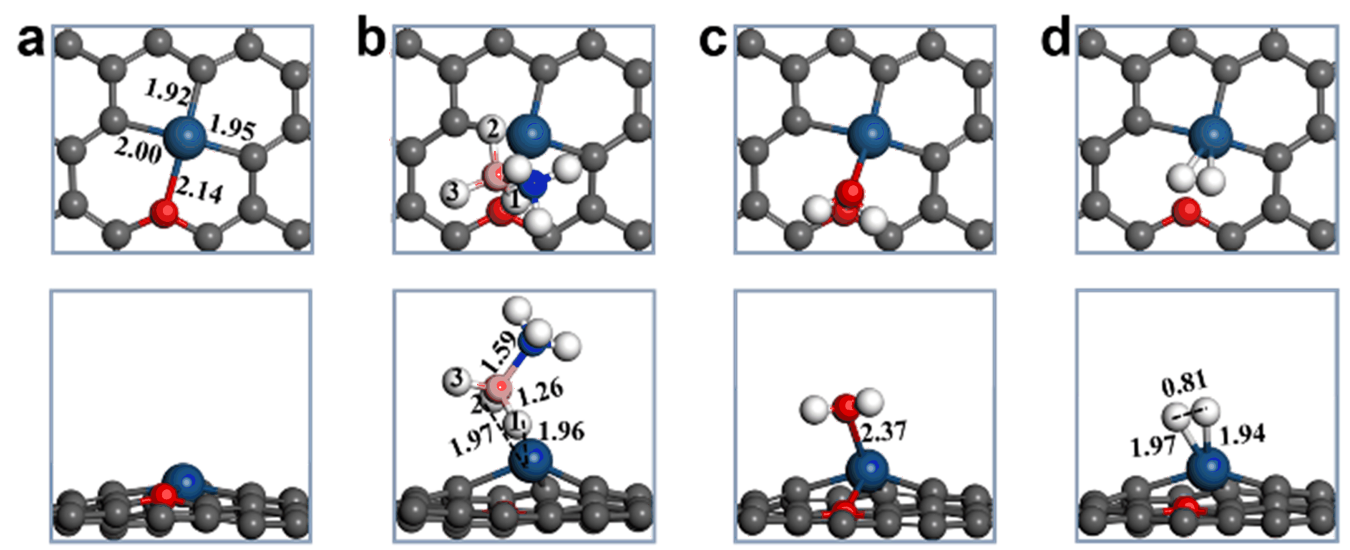

FIG. 1 Top and side views of the most stable configuration of a single Pt atom adsorbed on the Gr-O sheet (a), the optimized structures of $\mathrm{NH}_{3} \mathrm{BH}_{3}$ (b), $\mathrm{H}_{2} \mathrm{O}$ (c), and $\mathrm{H}_{2}$ (d) adsorbed on the $\mathrm{Pt}_{1} / \mathrm{Gr}-\mathrm{O}$ surface, respectively. The black, red, celadon, pink, blue, and white spheres represent $\mathrm{C}, \mathrm{O}, \mathrm{Pt}, \mathrm{B}, \mathrm{N}$, and $\mathrm{H}$ atoms, respectively. Critical bond lengths are labeled (in unit of $\AA$ ).

distances between $\mathrm{Pt}$ and two hydrogen atoms are 1.96 and $1.97 \AA$, respectively. For the interaction between $\mathrm{Pt}$ and $\mathrm{H}$, the two $\mathrm{B}-\mathrm{H}$ bonds are elongated to 1.26 and $1.27 \AA$ from $1.21 \AA$ in isolated solvated $\mathrm{NH}_{3} \mathrm{BH}_{3}$. Meanwhile, the $\mathrm{B}-\mathrm{N}$ bond is shortened by $0.03 \AA$. The changes in the $\mathrm{B}-\mathrm{H}$ and $\mathrm{B}-\mathrm{N}$ bond lengths agree with the results of $\mathrm{NH}_{3} \mathrm{BH}_{3}$ adsorbed on $\mathrm{Pd}_{2} / \mathrm{MgO}$ and $\mathrm{Pd}_{4} / \mathrm{MgO}[45]$.

The adsorption energy of one $\mathrm{H}_{2} \mathrm{O}$ molecule on $\mathrm{Pt}_{1} / \mathrm{Gr}-\mathrm{O}$ is calculated as $0.2 \mathrm{kcal} / \mathrm{mol}$, which is much lower than that of $\mathrm{NH}_{3} \mathrm{BH}_{3}$. The distance between the oxygen atom in the $\mathrm{H}_{2} \mathrm{O}$ molecule and $\mathrm{Pt}$ atom is $2.37 \AA$, as shown in FIG. 1(c), which also suggests a weak interaction between water and $\mathrm{Pt}_{1} / \mathrm{Gr}-\mathrm{O}$. The adsorption of one hydrogen molecule is also investigated. With molecularly adsorbed configuration as shown in FIG. 1(d), the adsorption energy is calculated as $2.8 \mathrm{kcal} / \mathrm{mol}$, which indicates the molecularly adsorbed hydrogen is ready to desorb from the catalyst. The bond length of $\mathrm{H}-\mathrm{H}$ is elongated to $0.81 \AA$ and two $\mathrm{Pt}-\mathrm{H}$ bond lengths are 1.94 and $1.97 \AA$, respectively.

\section{B. The elementary reactions of $\mathrm{NH}_{3} \mathrm{BH}_{3}$ hydrolysis on the $\mathrm{Pt}_{1} / \mathrm{Gr}-\mathrm{O}$ surface}

\section{The $\mathrm{B}-\mathrm{H}$ bond activation pathways}

Two possible mechanisms have been proposed to initiate the hydrolysis of $\mathrm{NH}_{3} \mathrm{BH}_{3}$. One is the bond breakage of $\mathrm{B}-\mathrm{N}$ bonds attacked by $\mathrm{H}_{2} \mathrm{O}$ molecules [10] and the other is the dehydrogenation of $\mathrm{BH}_{3}$ group [26]. $\mathrm{On} \mathrm{Pt}_{1} / \mathrm{Gr}-\mathrm{O}$, the energy barrier of $\mathrm{B}-\mathrm{N}$ bond breakage with the help of one water molecule is calculated as high as $37.7 \mathrm{kcal} / \mathrm{mol}$ (FIG. S1(a) in supplementary materials), which is similar to the result over $\mathrm{Ni}_{2} \mathrm{P}$ nanoparticles $(38.1 \mathrm{kcal} / \mathrm{mol})$ [19]. While the energy barrier of $\mathrm{B}-\mathrm{H}$ bond breaking is only $11.3 \mathrm{kcal} / \mathrm{mol}$, which indicates the adsorbed $\mathrm{NH}_{3} \mathrm{BH}_{3}$ molecule prefers $\mathrm{B}-\mathrm{H}$ bond breaking rather than $\mathrm{B}-\mathrm{N}$ bond breaking. At transition state $\mathrm{TS} 1$, a $\mathrm{Pt}-\mathrm{H}-\mathrm{B}$ three-membered ring configuration is formed, and the $\mathrm{Pt}-\mathrm{H}, \mathrm{B}-\mathrm{H}$, and $\mathrm{Pt}-\mathrm{B}$ distances are $1.64,1.84$, and $2.41 \AA$ as shown in FIG. 2, respectively. After the breaking of $\mathrm{B}-\mathrm{H}$ bond, the hydrogen atom locates at the bridge site of $\mathrm{Pt}-\mathrm{C}$ and the ${ }^{*} \mathrm{BH}_{2} \mathrm{NH}_{3}$ group binds to $\mathrm{Pt}$ site with the $\mathrm{Pt}-\mathrm{B}$ bond length of $2.21 \AA$ (I2). The carbon atom near the $\mathrm{Pt}$ atom is also active for trapping hydrogen atom, which resembles the $\mathrm{Fe}-\mathrm{C}$ bridge site for $\mathrm{NH}_{3} \mathrm{BH}_{3}$ dehydrogenation on prototype iron pincer catalyst [46].

For the next step, four possible reaction pathways (i.e., $\mathrm{N}-\mathrm{H}$ bond breaking to form $\mathrm{BH}_{2} \mathrm{NH}_{2}$, directly producing a gas phase hydrogen molecule, hydrolysis of ${ }^{*} \mathrm{BH}_{2} \mathrm{NH}_{3}$, and the second $\mathrm{B}-\mathrm{H}$ bond breaking to form a molecularly adsorbed hydrogen) are investigated as shown in FIG. S1 (b) -(d) in supplementary materials and FIG. 2. The energy barriers of these four possible elementary steps are calculated as 33.9, 21.4, 21.4, and $10.0 \mathrm{kcal} / \mathrm{mol}$, respectively. The formation of a molecularly adsorbed hydrogen via bond breaking of the second $\mathrm{B}-\mathrm{H}$ bond has the lowest energy barrier. At transition state (TS2), the $\mathrm{C}-\mathrm{H}$ and $\mathrm{Pt}-\mathrm{B}$ bond lengths elongate by 0.76 and $0.12 \AA$, respectively. The formed molecular hydrogen weakly adsorbs on $\mathrm{Pt}_{1} / \mathrm{Gr}-\mathrm{O}$ and easily desorbs from catalyst with an energy barrier of $0.9 \mathrm{kcal} / \mathrm{mol}$ via transition state (TS3). The production of the first hydrogen releases $1.8 \mathrm{kcal} / \mathrm{mol}$ relative to the adsorbed $\mathrm{NH}_{3} \mathrm{BH}_{3}$ system.

\section{Hydroxylation pathways of $\mathrm{B}$ atom in $\mathrm{NH}_{3} \mathrm{BH}_{3}$}

After desorption of the first hydrogen molecule, the left ${ }^{*} \mathrm{BHNH}_{3}$ adsorbs at bridge site of $\mathrm{Pt}-\mathrm{C}$. Four possible ways of the evolution of ${ }^{*} \mathrm{BHNH}_{3}$ including the breaking of $\mathrm{B}-\mathrm{H}$ bond, the breaking of $\mathrm{N}-\mathrm{H}$ bond 


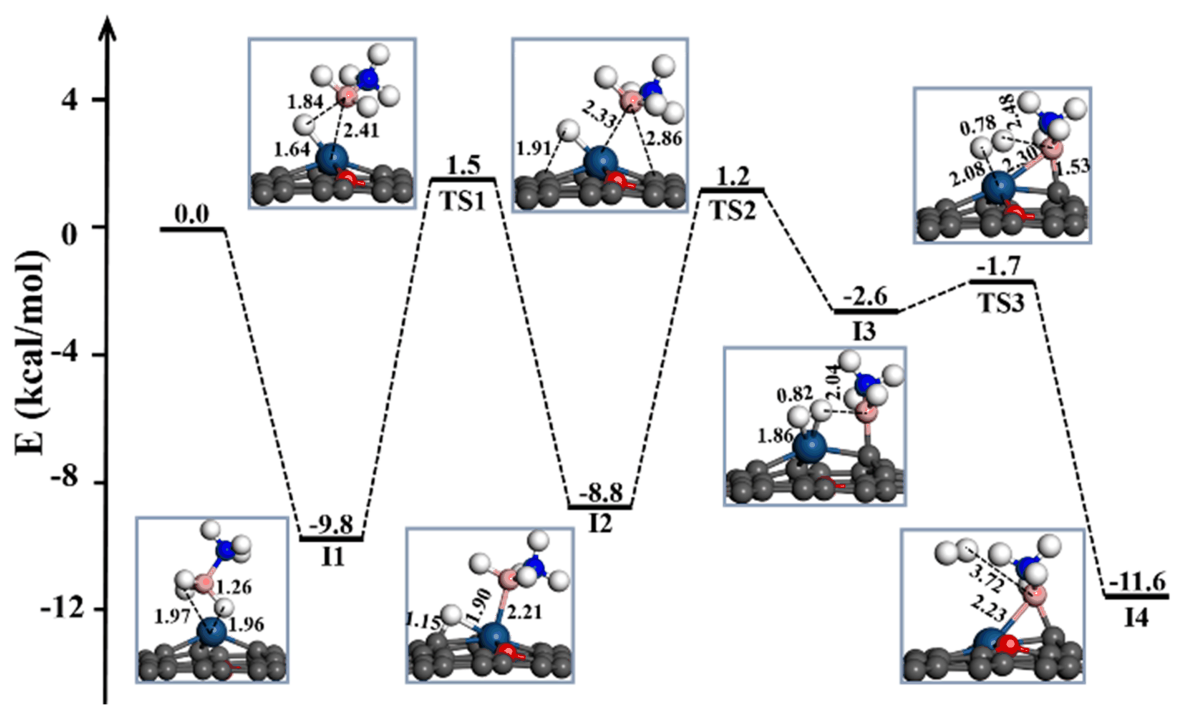

FIG. 2 The relative energy profiles of the releasing of the first hydrogen molecule from $\mathrm{NH}_{3} \mathrm{BH}_{3}$ catalyzed by $\mathrm{Pt}_{1} / \mathrm{Gr}_{-} \mathrm{O}$. Critical bond lengths are labeled (in unit of $\AA$ ).

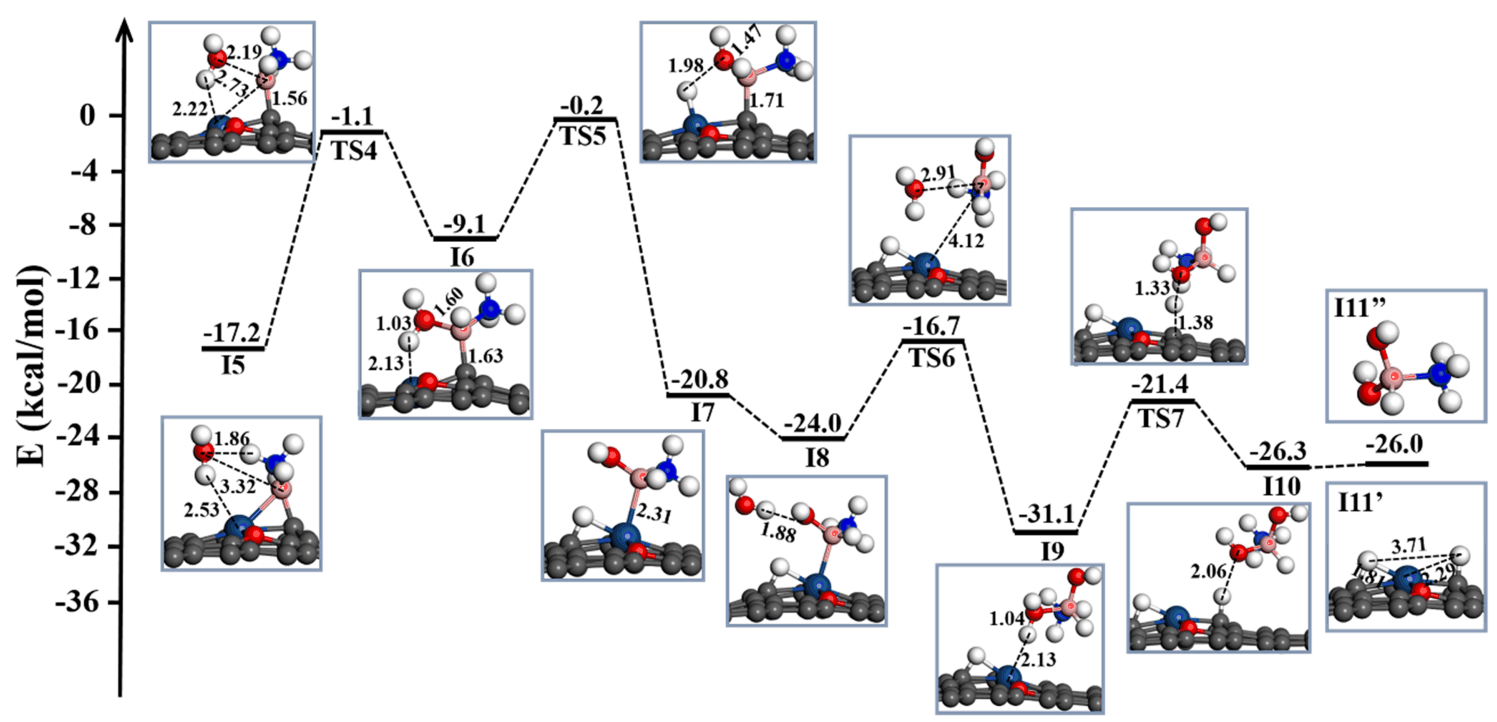

FIG. 3 The relative energy profiles of the hydrolysis of $\mathrm{NH}_{3} \mathrm{BH}_{3}$ by the first and second $\mathrm{H}_{2} \mathrm{O}$ molecules on $\mathrm{Pt} / \mathrm{Gr}-\mathrm{O}$. Critical bond lengths are labeled (in unit of $\AA$ ).

and also the attachment of water molecule to form $\mathrm{Pt}$ (or $\mathrm{C}$ ) bound ${ }^{*} \mathrm{BH}\left(\mathrm{H}_{2} \mathrm{O}\right) \mathrm{NH}_{3}$ are considered as shown in FIG. $\mathrm{S} 2(\mathrm{a})-(\mathrm{c})$ in supplementary materials and FIG. 3. The energy barriers are calculated as 42.7, $32.1,23.0$, and $16.1 \mathrm{kcal} / \mathrm{mol}$ for the four possible reaction ways, respectively. The combination of a $\mathrm{H}_{2} \mathrm{O}$ molecule with ${ }^{*} \mathrm{BHNH}_{3}$ to form $\mathrm{C}-\mathrm{BH}\left(\mathrm{H}_{2} \mathrm{O}\right) \mathrm{NH}_{3}$ is the most kinetically favorable way. At initial state, a $\mathrm{H}_{2} \mathrm{O}$ molecule interacts with the ${ }^{*} \mathrm{BHNH}_{3}$ group through the weak $\mathrm{O} \cdots \mathrm{H}-\mathrm{N}$ hydrogen bond with bond energy of $-6.0 \mathrm{kcal} / \mathrm{mol}$ as the intermediate $\mathrm{I} 5$ and the geometric parameters are shown in FIG. 3. At transition state (TS4) the distance between $\mathrm{O}$ and $\mathrm{B}$ is shortened to $2.19 \AA$ from $3.32 \AA$ in $\mathrm{I} 5$. The formed ${ }^{*} \mathrm{BH}\left(\mathrm{H}_{2} \mathrm{O}\right) \mathrm{NH}_{3}$ group locates on the $\mathrm{C}$ atom neighboring to $\mathrm{Pt}$ atom (I6). The $\mathrm{O}-\mathrm{H}$ bond pointing to $\mathrm{Pt}$ atom is $0.04 \AA$ longer than the other one. The elongated $\mathrm{O}-\mathrm{H}$ bond easily breaks with an energy barrier of $8.9 \mathrm{kcal} / \mathrm{mol}$, the released reaction energy is $11.7 \mathrm{kcal} / \mathrm{mol}$. At transition state (TS5), the $\mathrm{O}-\mathrm{H}$ bond length is $1.98 \AA$. The detached hydrogen atom adsorbs on the $\mathrm{Pt}-\mathrm{C}$ bridge site and the ${ }^{*} \mathrm{BH}(\mathrm{OH}) \mathrm{NH}_{3}$ group binds to $\mathrm{Pt}$ atom (I7).

Then for the evolution of I7, the most favorable way is the attachment of the second $\mathrm{H}_{2} \mathrm{O}$ molecule to ${ }^{*} \mathrm{BH}(\mathrm{OH}) \mathrm{NH}_{3}$, which is shown in FIG. 3 as the formation of I9 from I8 via TS6. The formation of ${ }^{*} \mathrm{BH}(\mathrm{OH})\left(\mathrm{H}_{2} \mathrm{O}\right) \mathrm{NH}_{3}$ by combination of a $\mathrm{H}_{2} \mathrm{O}$ molecule and ${ }^{*} \mathrm{BH}(\mathrm{OH}) \mathrm{NH}_{3}$ is an exothermic step $(7.1 \mathrm{kcal} / \mathrm{mol})$ 


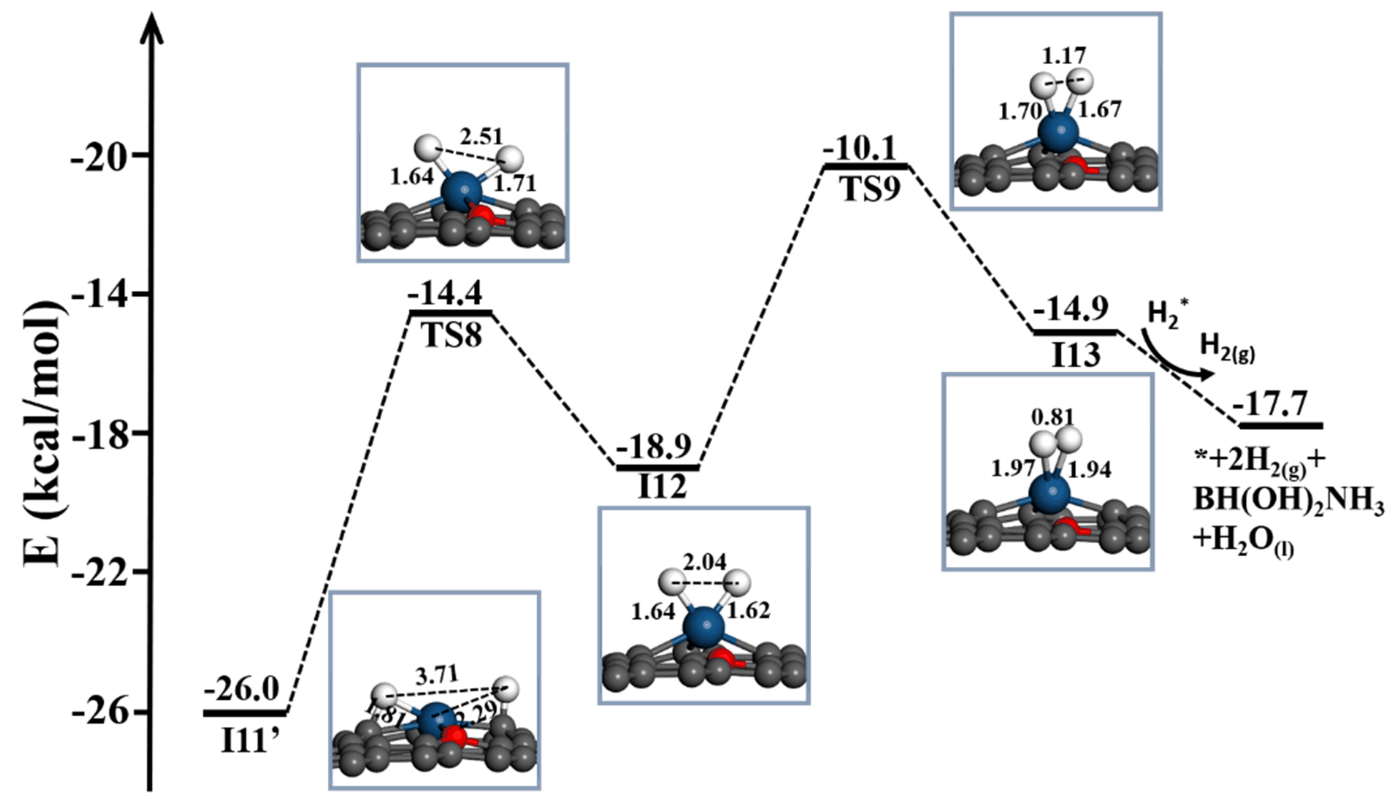

FIG. 4 The relative energy (with I11" included) profiles of the recovery of $\mathrm{Pt}_{1} / \mathrm{Gr}-\mathrm{O}$ catalyst. Critical bond lengths are labeled (in unit of $\AA$ ).

with a relatively low energy barrier of $7.3 \mathrm{kcal} / \mathrm{mol}$. At transition state (TS6), ${ }^{*} \mathrm{BH}(\mathrm{OH}) \mathrm{NH}_{3}$ leaves from the $\mathrm{Pt}$ atom with the $\mathrm{Pt}-\mathrm{B}$ distance of $4.12 \AA$ and the bond distance of $\mathrm{O}-\mathrm{B}$ is $2.91 \AA$. At $\mathrm{I} 9,{ }^{*} \mathrm{BH}(\mathrm{OH})\left(\mathrm{H}_{2} \mathrm{O}\right) \mathrm{NH}_{3}$ adsorbs on the catalyst through one hydrogen atom in $\left(\mathrm{H}_{2} \mathrm{O}\right)$ fragment and the $\mathrm{O}-\mathrm{H}$ bond length is elongated to $1.04 \AA$. The breaking of the elongated $\mathrm{O}-\mathrm{H}$ bond needs to conquer an energy barrier of $9.7 \mathrm{kcal} / \mathrm{mol}$ and it is an endothermic process with a reaction energy of 4.8 $\mathrm{kcal} / \mathrm{mol}$. The formed $\mathrm{BH}(\mathrm{OH})_{2} \mathrm{NH}_{3}$ physically adsorbs on the $\mathrm{Pt}_{1} / \mathrm{Gr}-\mathrm{O}$ surface and the second isolated $\mathrm{H}$ atom adsorbs on the $\mathrm{C}$ atom (I10). The adsorption energy of $\mathrm{BH}(\mathrm{OH})_{2} \mathrm{NH}_{3}$ is only $0.3 \mathrm{kcal} / \mathrm{mol}$ and it is supposed that the formed $\mathrm{BH}(\mathrm{OH})_{2} \mathrm{NH}_{3}$ can easily dissolve in water solution.

\section{Recovery of $\mathrm{Pt}_{1} / \mathrm{Gr}-\mathrm{O}$ catalyst}

After the releasing of $\mathrm{BH}(\mathrm{OH})_{2} \mathrm{NH}_{3}$, two hydrogen atoms present on $\mathrm{Pt}_{1} / \mathrm{Gr}-\mathrm{O}\left(\mathrm{I}_{1}^{\prime}\right)$. By removing hydrogen atoms, the $\mathrm{Pt}_{1} / \mathrm{Gr}-\mathrm{O}$ catalyst can be recovered. The release of molecular hydrogen can be separated as the transfer of $\mathrm{C}$ bonded atomic hydrogen, the formation of chemically adsorbed molecular hydrogen and the desorption of hydrogen molecule. H transfers from I11' to 112 via TS8 with an energy barrier of $11.6 \mathrm{kcal} / \mathrm{mol}$. The distance between two hydrogen atoms are 3.71 , 2.51, and $2.04 \AA$ in $\mathrm{I}^{\prime} 1^{\prime}$, TS8, and I12, respectively. Then the two hydrogen atoms combine with each other to form chemically adsorbed dihydrogen with an energy barrier of $8.8 \mathrm{kcal} / \mathrm{mol}$. At transition state (TS9), the $\mathrm{H}-\mathrm{H}$ bond length is $1.17 \AA$. The adsorption energy of chemically adsorbed hydrogen molecule is $2.8 \mathrm{kcal} / \mathrm{mol}$, which indicates that the formed dihydrogen is ready to desorb from the catalyst. After the releasing of gas phase hydrogen molecule, the $\mathrm{Pt}_{1} / \mathrm{Gr}-\mathrm{O}$ catalyst recovers. The recovery of catalyst is an endothermic process with energy of $8.3 \mathrm{kcal} / \mathrm{mol}$, which is easy to be conquered at room temperature if the entropy increasing is considered for the releasing of gas phase hydrogen molecule.

\section{The release of the third hydrogen}

Now, only two hydrogen molecules are released from one $\mathrm{BH}_{3} \mathrm{NH}_{3}$ molecule. The third molecular hydrogen comes from further hydrolysis of formed solvated $\mathrm{BH}(\mathrm{OH})_{2} \mathrm{NH}_{3}$. In solvated $\mathrm{BH}(\mathrm{OH})_{2} \mathrm{NH}_{3}$, the $\mathrm{B}-\mathrm{N}$ bond length is $1.67 \AA$, which is $0.05 \AA$ longer than that of the solvated isolated $\mathrm{BH}_{3} \mathrm{NH}_{3}$. The $\mathrm{B}-\mathrm{N}$ bond is easy to be broken with the attack of one water molecule with an energy barrier of $10.6 \mathrm{kcal} / \mathrm{mol}$, which is close to the reported $\mathrm{B}-\mathrm{N}$ bond dissociation energy of $10.0 \mathrm{kcal} / \mathrm{mol}$ in $\mathrm{NH}_{3} \mathrm{BH}_{2} \mathrm{OH}$ [47] and much lower than that of the $\mathrm{B}-\mathrm{N}$ bond breaking in $\mathrm{BH}_{3} \mathrm{NH}_{3}$ $(38.0 \mathrm{kcal} / \mathrm{mol})$. After the cleavage of $\mathrm{B}-\mathrm{N}$ bond, the resulted $\mathrm{BH}(\mathrm{OH})_{2}, \mathrm{H}_{2} \mathrm{O}$ and $\mathrm{NH}_{3}$ molecules form a cluster (I15) by $\mathrm{HO} \cdots \mathrm{HO}-\mathrm{H}$ and $\mathrm{NH} \cdots \mathrm{OH}_{2}$ hydrogen bonds. Then a complex $\mathrm{BH}(\mathrm{OH})_{3} \cdots \mathrm{NH}_{4}$ (I16) is formed by the dissociation of water with an energy barrier of $2.8 \mathrm{kcal} / \mathrm{mol}$. The hydrogen bond length in I16 is $1.49 \AA$ and the distance between the left $\mathrm{H}(-\mathrm{B})$ and the nearest $\mathrm{H}(-\mathrm{N})$ is $3.22 \AA$. The combination of the two hydrogen atoms conquers an energy barrier of $11.6 \mathrm{kcal} / \mathrm{mol}$ and releases energy of $8.6 \mathrm{kcal} / \mathrm{mol}$. At transition state (TS13), the bond lengths of $\mathrm{B}-\mathrm{H}$ and 


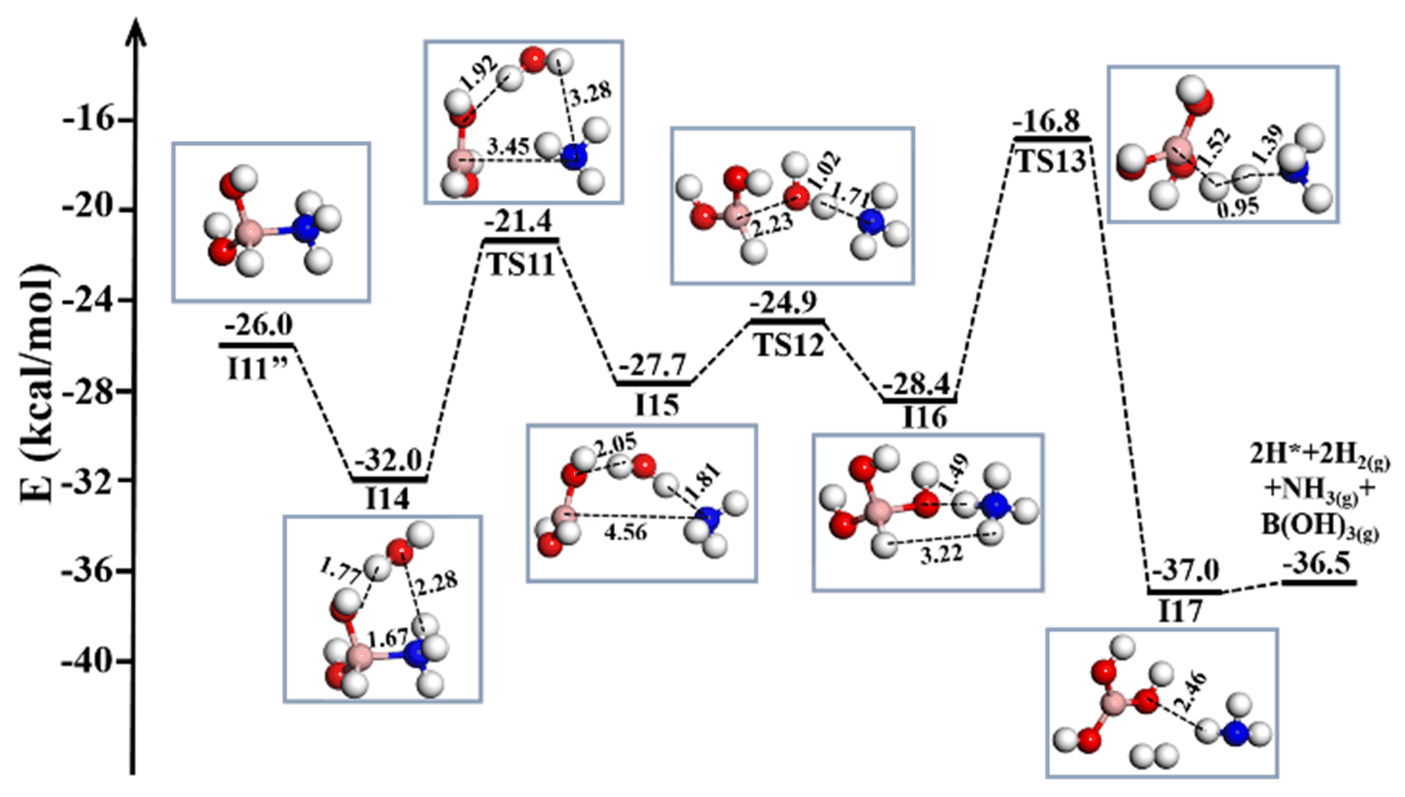

FIG. 5 The relative energy (with I11' included) profiles of hydrolysis of the resulted $\mathrm{BH}(\mathrm{OH})_{2} \mathrm{NH}_{3}$ group in water solution. Critical bond lengths are labeled (in unit of $\AA$ ).

$\mathrm{N}-\mathrm{H}$ are elongated to 1.52 and $1.39 \AA$, respectively, while the $\mathrm{H}-\mathrm{H}$ distance is shortened to $0.95 \AA$. The generated products also include $\mathrm{NH}_{3}$ and $\mathrm{B}(\mathrm{OH})_{3}$. The species of products have not been definitely determined yet. Banu et al. used $\mathrm{B}(\mathrm{OH})_{3}, \mathrm{H}_{2}$ and $\mathrm{NH}_{3}$ as the products for hydrolysis of $\mathrm{NH}_{3} \mathrm{BH}_{3}$ without catalysts in gas phase and aqueous phase [44]. Chen et al. proposed that a $\mathrm{NH}_{4} \mathrm{~B}(\mathrm{OH})_{4}-\mathrm{B}(\mathrm{OH})_{3}$ mixture rather than $\mathrm{NH}_{4} \mathrm{BO}_{2}$ is the main B-containing byproducts after hydrolysis of $\mathrm{BH}_{3} \mathrm{NH}_{3}$ catalyzed by a Pt/CNT catalyst [27]. But this may be the evolution of hydrolysis species, which are not critical for the production of hydrogen.

The hydrolysis of the resulted $\mathrm{BH}(\mathrm{OH})_{2}$ group in I15 over $\mathrm{Pt}_{1} / \mathrm{Gr}-\mathrm{O}$ surface is also considered. It is found a $\mathrm{BH}(\mathrm{OH})_{2}$ molecule adsorbs weakly on $\mathrm{Pt}_{1} / \mathrm{Gr}-\mathrm{O}$ catalyst with the adsorption energy of $-0.04 \mathrm{kcal} / \mathrm{mol}$, which is much lower than that of $\mathrm{NH}_{3} \mathrm{BH}_{3}(-9.8 \mathrm{kcal} / \mathrm{mol})$. The hydrolysis of $\mathrm{BH}(\mathrm{OH})_{2}$ groups can also proceed on $\mathrm{Pt}_{1} / \mathrm{Gr}-\mathrm{O}$ (as shown in FIG. S3 in supplementary materials) without the precover with $\mathrm{NH}_{3} \mathrm{BH}_{3}$ or atomic hydrogen. The energy barrier of $\mathrm{BH}(\mathrm{OH})_{2}$ hydrolysis on $\mathrm{Pt}_{1} / \mathrm{Gr}-\mathrm{O}$ is significantly reduced to $4.8 \mathrm{kcal} / \mathrm{mol}$ compared to that $(39.5 \mathrm{kcal} / \mathrm{mol})$ of $\mathrm{BH}(\mathrm{OH})_{2}$ hydrolysis without catalysts reported by Banu et al. [44].

Based on the aforementioned reaction pathways, the optimal reaction processes of $\mathrm{NH}_{3} \mathrm{BH}_{3}$ hydrolysis on $\mathrm{Pt}_{1} / \mathrm{Gr}-\mathrm{O}$ are depicted in FIG. 6 as: (i) the preferential adsorption of one $\mathrm{NH}_{3} \mathrm{BH}_{3}$ molecule on $\mathrm{Pt}_{1} / \mathrm{Gr}-\mathrm{O}$ and the activation of $\mathrm{B}-\mathrm{H}$ bonds, (ii) the first $\mathrm{B}-\mathrm{H}$ bond breaking, (iii) the formation of molecularly adsorbed dihydrogen from the second $\mathrm{B}-\mathrm{H}$ bond breaking, (iv) the desorption of the first gas phase hydrogen molecule; (v) the attacking of the first water molecule, (vi) the attack-

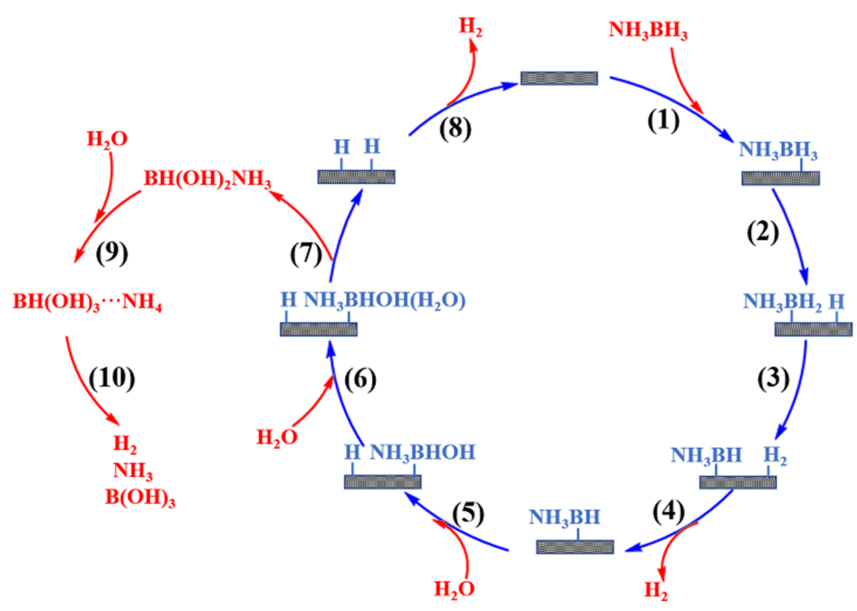

FIG. 6 Proposed mechanism for $\mathrm{NH}_{3} \mathrm{BH}_{3}$ hydrolysis over $\mathrm{Pt}_{1} / \mathrm{Gr}-\mathrm{O}$ surface.

ing of the second water molecule, (vii) the desorption of $\mathrm{BH}(\mathrm{OH})_{2} \mathrm{NH}_{3}$, (viii) the desorption of the second gas phase hydrogen molecule and the recovery of catalyst, (ix) the attacking of the third water molecule, $(\mathrm{x})$ the releasing of the third hydrogen molecule and the formation of final products.

Through the whole reaction pathways for $\mathrm{NH}_{3} \mathrm{BH}_{3}$ hydrolysis, it is found that the attacking of first $\mathrm{H}_{2} \mathrm{O}$ molecule to ${ }^{*} \mathrm{BHNH}_{3} \quad\left({ }^{*} \mathrm{BHNH}_{3}+\mathrm{H}_{2} \mathrm{O} \rightarrow\right.$ $\left.{ }^{*} \mathrm{~B}\left(\mathrm{H}_{2} \mathrm{O}\right) \mathrm{HNH}_{3}\right)$ is the rate-limiting step on $\mathrm{Pt}_{1} / \mathrm{Gr}-\mathrm{O}$ with an energy barrier of $16.1 \mathrm{kcal} / \mathrm{mol}$. To gain more insight into the origin of the reaction activity of $\mathrm{H}_{2} \mathrm{O}$ molecules reacting with the ${ }^{*} \mathrm{BNH}_{3}$ group, the local density of states (LDOS) projected onto B atom and 

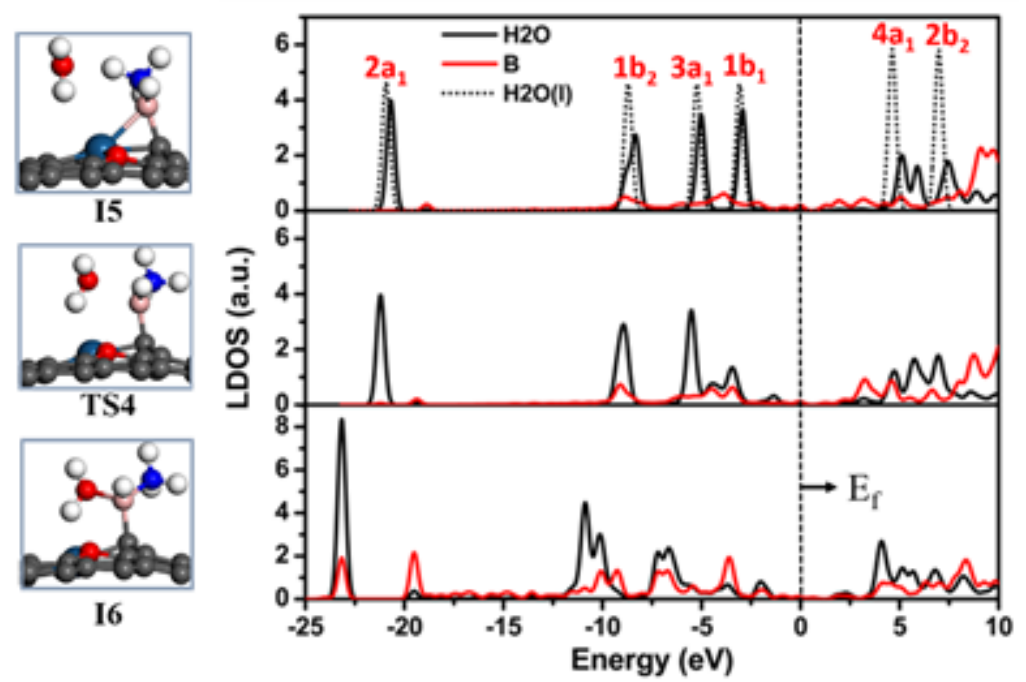

FIG. 7 Left panels are structures of I5, TS4, and I6 in FIG. 3, right panel is the local density of states (LDOS) projected onto $\mathrm{B}$ atom and $\mathrm{H}_{2} \mathrm{O}$ molecule in the $\mathrm{I} 5$, TS4, and $\mathrm{I} 6$ over $\mathrm{Pt}_{1} / \mathrm{Gr}-\mathrm{O}$ surface. $E_{\mathrm{f}}$ denotes the Fermi level. The dot dashed line shows the density states (energy levels) of isolated water molecule with solvent effect included. The energy levels are shifted according to the $\mathrm{O} 1$ s orbitals of water molecule in $\mathrm{I} 5$ and $\mathrm{H}_{2} \mathrm{O}(\mathrm{l})$.

$\mathrm{H}_{2} \mathrm{O}$ molecule in the I5, TS4, and $\mathrm{I} 6$ over $\mathrm{Pt}_{1} / \mathrm{Gr}-\mathrm{O}$ has been split as shown in FIG. 7. The highest occupied molecular orbital (HOMO) of water, $1 \mathrm{~b}_{1}$ state, is contributed by the lone pair electrons of oxygen atom. $\mathrm{B}$ atom has empty orbitals which can accept electrons from donation atom. At TS4, the density states of $1 b_{1}$ expanded and slightly overlapped with the orbitals of $\mathrm{B}$ atom. For the interaction between water and ${ }^{*} \mathrm{BHNH}_{3}$ group, the empty orbitals shift towards low energy direction. At $\mathrm{I} 6$, the orbitals of water molecule effectively overlap with that of B atom, which indicates the chemical bonding between water molecule and B atom. For the donation of lone pair electrons, the density of states of water molecule decreases and that of $\mathrm{B}$ atom increases below fermi level. The orbitals above fermi level shift towards low energy direction for the formation of chemical bond, which makes the hydrolysis of ${ }^{*} \mathrm{BHNH}_{3}$ group proceed.

\section{CONCLUSION}

In conclusion, the $\mathrm{NH}_{3} \mathrm{BH}_{3}$ hydrolysis mechanisms on single $\mathrm{Pt}$ atom anchored to the plane of graphene with a defective carbon atom replaced by an oxygen atom were examined by using first-principles calculations. The $\mathrm{Pt}_{1} / \mathrm{Gr}-\mathrm{O}$ catalyst prefers to activate the $\mathrm{B}-\mathrm{H}$ bonds, and first hydrogen molecule is released by two detached $\mathrm{H}$ atoms from $\mathrm{B}-\mathrm{H}$ bonds. The left ${ }^{*} \mathrm{BHNH}_{3}$ combines with two $\mathrm{H}_{2} \mathrm{O}$ molecules to proceed the hydrolysis process. The combination of left ${ }^{*} \mathrm{BHNH}_{3}$ with the first $\mathrm{H}_{2} \mathrm{O}$ molecule is the rate-limiting step with an energy barrier of $16.1 \mathrm{kcal} / \mathrm{mol}$. Both attached water molecules detach one hydrogen atom to form $\mathrm{NH}_{3} \mathrm{BH}(\mathrm{OH})_{2}$, which can be easily hydrolyzed in water solvent to release one hydrogen molecule without catalyst. By combination and releasing of the two surface left hydrogen atoms, $\mathrm{Pt}_{1} / \mathrm{Gr}-\mathrm{O}$ can be recovered. A whole mechanism of $\mathrm{NH}_{3} \mathrm{BH}_{3}$ hydrolysis over solid catalysts is presented for the first time. Based on the calculated results the $\mathrm{Pt}_{1} / \mathrm{Gr}-\mathrm{O}$ catalyst exhibits high catalytic activity for $\mathrm{NH}_{3} \mathrm{BH}_{3}$ hydrolysis at room temperature. Thus $\mathrm{Pt}$ single atoms anchored at a designed configuration on graphene nanosheet can perform high activity for hydrolysis of $\mathrm{NH}_{3} \mathrm{BH}_{3}$ at room temperature.

Supplementary materials: The bond breakage of $\mathrm{B}-\mathrm{N}$ bond in $\mathrm{NH}_{3} \mathrm{BH}_{3}$ attacked by one $\mathrm{H}_{2} \mathrm{O}$ molecule; the three possible reaction pathways of the ${ }^{*} \mathrm{BH}_{2} \mathrm{NH}_{3}$ including $\mathrm{N}-\mathrm{H}$ bond breaking to form $\mathrm{BH}_{2} \mathrm{NH}_{2}$, direct production of a gas phase hydrogen molecule, and hydrolysis of ${ }^{*} \mathrm{BH}_{2} \mathrm{NH}_{3}$; the three possible reaction pathways of the ${ }^{*} \mathrm{BHNH}_{3}$ including the $\mathrm{B}-\mathrm{H}$ bond breaking, the $\mathrm{N}-\mathrm{H}$ bond breaking, and the attachment of one water molecule to form $\mathrm{Pt}$ bound $\mathrm{BH}\left(\mathrm{H}_{2} \mathrm{O}\right) \mathrm{NH}_{3}$; and the hydroxylation pathways of $\mathrm{BH}(\mathrm{OH})_{2}$ on $\mathrm{Pt}_{1} / \mathrm{Gr}-\mathrm{O}$ are shown in FIG. S1-S3.

\section{ACKNOWLEDGMENTS}

This work is supported by the National Natural Science Foundation of China (No.21473167 and No.21688102) and the National Key Research and Development Program of China (No.2016YFA0200604), and the Fundamental Research Funds for the Central Universities (WK3430000005, WK2340000065), and the China Scholarship Council (CSC) (No.201706345015). We used computational resources of Super-computing Center of University of Science and Technology of 
China, Guangzhou and Shanghai Supercomputer Centers.

[1] U. Eberle, M. Felderhoff, and F. Schüth, Angew. Chem. Int. Ed. 48, 6608 (2009).

[2] T. B. Marder, Angew. Chem. Int. Ed. 46, 8116 (2007).

[3] C. W. Hamilton, R. T. Baker, A. Staubitz, and I. Manners, Chem. Soc. Rev. 38, 279 (2009).

[4] J. Yang, A. Sudik, C. Wolverton, and D. J. Siegel, Chem. Soc. Rev. 39, 656 (2010).

[5] M. Yadav and Q. Xu, Energy Environ. Sci. 5, 9698 (2012).

[6] F. H. Stephens, V. Pons, and R. Tom Baker, Dalton Trans. 2, 2613 (2007).

[7] B. Peng and J. Chen, Energy Environ. Sci. 1, 479 (2008).

[8] A. Staubitz, A. P. M. Robertson, and I. Manners, Chem. Rev. 110, 4079 (2010).

[9] A. Karkamkar, C. Aardahl, and T. Autrey, Mater. Sci. 10, 6 (2007).

[10] M. Chandra and Q. Xu, J. Power Sources 168, 135 (2007).

[11] H. Shioyama and Q. Xu, J. Am. Chem. Soc. 134, 13926 (2012).

[12] W. Chen, J. Ji, X. Feng, X. Duan, G. Qian, P. Li, X. Zhou, D. Chen, and W. Yuan, J. Am. Chem. Soc. 136, 16736 (2014).

[13] W. Chen, J. Ji, X. Duan, G. Qian, P. Li, X. Zhou, D. Chen, and W. Yuan, Chem. Commun. 50, 2142 (2014).

[14] Y. Chen, X. Yang, M. Kitta, and Q. Xu, Nano Res. 10, 3811 (2017).

[15] K. Aranishi, Q. L. Zhu, and Q. Xu, ChemCatChem. 6, 1375 (2014)

[16] J. Hu, Z. Chen, M. Li, X. Zhou, and H. Lu, ACS Appl. Mater. Interfaces 6, 13191 (2014).

[17] Z. Li, T. He, L. Liu, W. Chen, M. Zhang, G. Wu, and P. Chen, Chem. Sci. 8, 781 (2017).

[18] P. Liu, X. Gu, K. Kang, H. Zhang, J. Cheng, and H. $\mathrm{Su}, \mathrm{ACS}$ Appl. Mater. Interfaces 9, 10759 (2017).

[19] C.Y. Peng, L. Kang, S. Cao, Y. Chen, Z. S. Lin, and W. F. Fu, Angew. Chem. Int. Ed. 54, 15725 (2015).

[20] G. Zhao, J. Zhong, J. Wang, T. K. Sham, X. Sun, and S. T. Lee, Nanoscale 7, 9715 (2015).

[21] C. Wang, J. Tuninetti, Z. Wang, C. Zhang, R. Ciganda, L. Salmon, S. Moya, J. Ruiz, and D. Astruc, J. Am. Chem. Soc. 139, 11610 (2017).

[22] K. Guo, H. Li, and Z. Yu, ACS Appl. Mater. Interfaces 10, 517 (2018).

[23] Q. Xu and M. Chandra, J. Power Sources 163, 364 (2006).

[24] M. Kaya, M. Zahmakiran, S. Özkar, and M. Volkan, ACS Appl. Mater. Interfaces 4, 3866 (2012).
[25] D. Zhang, P. Liu, S. Xiao, X. Qian, H. Zhang, M. Wen, Y. Kuwahara, K. Mori, H. Li, and H. Yamashita, Nanoscale 8, 7749 (2016).

[26] H. Ma and C. Na, ACS Catal. 5, 1726 (2015).

[27] W. Chen, D. Li, Z. Wang, G. Qian, Z. Sui, X. Duan, X. Zhou, I. Yeboah, and D. Chen, AIChE J. 63, 60 (2017).

[28] W. Chen, D. Li, C. Peng, G. Qian, X. Duan, D. Chen, and X. Zhou, J. Catal. 356, 186 (2017).

[29] Z. Li, T. He, D. Matsumura, S. Miao, A. Wu, L. Liu, G. Wu, and P. Chen, ACS Catal. 7, 6762 (2017).

[30] C. C. Hou, Q. Li, C. J. Wang, C. Y. Peng, Q. Q. Chen, H. F. Ye, W. F. Fu, C. M. Che, N. López, and Y. Chen, Energy Environ. Sci. 10, 1770 (2017).

[31] W. W. Zhan, Q. L. Zhu, and Q. Xu, ACS Catal. 6, 6892 (2016).

[32] B. Qiao, A. Wang, X. Yang, L. F. Allard, Z. Jiang, Y. Cui, J. Liu, J. Li, and T. Zhang, Nat. Chem. 3, 634 (2011).

[33] H. Zhang, T. Watanabe, M. Okumura, M. Haruta, and N. Toshima, Nat. Mater. 11, 49 (2012).

[34] X. Yang, A. Wang, B. Qiao, and J. Li, Acc. Chem. Res. 46, 1740 (2013)

[35] Y. Tang, X. Dai, Z. Yang, L. Pan, W. Chen, D. Ma, and Z. Lu, Phys. Chem. Chem. Phys. 16, 7887 (2014).

[36] S. Sun, G. Zhang, N. Gauquelin, N. Chen, J. Zhou, S. Yang, W. Chen, X. Meng, D. Geng, M. N. Banis, R. Li, S. Ye, S. Knights, G. A. Botton, T. K. Sham, and X. Sun, Sci. Rep. 3, 1775 (2013).

[37] H. Yan, H. Cheng, H. Yi, Y. Lin, T. Yao, C. Wang, J. Li, S. Wei, and J. Lu, J. Am. Chem. Soc. 137, 10484 (2015).

[38] H. Yan, Y. Lin, H. Wu, W. Zhang, Z. Sun, H. Cheng, W. Liu, C. Wang, J. Li, X. Huang, T. Yao, J. Yang, S. Wei, and J. Lu, Nat. Commun. 8, 1 (2017).

[39] B. Delley, Phys. Rev. B 66, 155125 (2002).

[40] J. P. Perdew, K. Burke, and M. Ernzerhof, Phys. Rev. Lett. 77, 3865 (1996).

[41] B. Delley, J. Chem. Phys. 92, 508 (1990).

[42] B. Delley, J. Chem. Phys. 113, 7756 (2000).

[43] A. Klamt and G. Schüürmann, J. Chem. Soc. Perkin Trans. 2, 799 (1993).

[44] T. Banu, T. Debnath, T. Ash, and A. K. Das, J. Chem. Phys. 143, 194305 (2015).

[45] M. Tong, Z. Yin, Y. Wang, and G. Chen, Int. J. Hydrogen Energy 38, 15285 (2013).

[46] Y. Zhang, Y. Zhang, Z. H. Qi, Y. Gao, W. Liu, and Y. Wang, Int. J. Hydrogen Energy 41, 17208 (2016).

[47] H. A. LeTourneau, R. E. Birsch, G. Korbeck, and J. L. Radkiewicz-Poutsma, J. Phys. Chem. A 109, 12014 (2005). 